\title{
WIND TUNNEL TESTS OF THE TU-154M AIRCRAFT AERODYNAMIC CHARACTERISTICS
}

\author{
Andrzej Krzysiak \\ Eukasiewicz Research Network - Institute of Aviation \\ Krakowska Av. 110/114, 02-256 Warsaw, Poland \\ tel.: +482284600 11, fax: +48228464432 \\ e-mail:andrzej.krzysiak@ilot.edu.pl
}

\begin{abstract}
Determination of possible manoeuvres to be performed by the aircraft requires knowledge of its aerodynamic characteristics including, in particular, characteristics of the aircraft at configuration with deflected control surfaces. In this article, the wind tunnel tests results of the model of passenger Tu-154M aircraft manufactured at the scale 1:40 are presented. The model was designed and manufactured by the Military University of Technology based on the Tu154M aircraft geometry obtained by full-scale object scanning. The model mapped all aircraft control surfaces, along with the gaps between these surfaces and the main wing part.

During the tests all the model's control surface like, flaps, ailerons, spoilers, slots, rudder, elevator and tail plane were deflected at the same deflection angles range as they are used in the full scale aircraft. The aerodynamic characteristics of the tested Tu-154M aircraft model were measured by the 6-component internal balance. Based on the obtained measurements the aircraft model aerodynamic coefficients were calculated. In the article the basic aerodynamic characteristics of the tested Tu-154M aircraft model i.e. lift, drag coefficients as well as pitching, yawing and rolling moment coefficients versus model angles of attack and sideslip angles were presented.

The tests were performed in the Institute of Aviation low speed wind tunnels $T-1$ of the $1.5 \mathrm{~m}$ diameter test section at the undisturbed velocity, $V \infty=40 \mathrm{~m} / \mathrm{s}$.
\end{abstract}

Keywords: applied aerodynamics, tests reliability, aerodynamic measurements.

\section{Introduction}

Reverse engineering, also called back engineering, is the process by which a fabricated object is deconstructed to reveal its designs, architecture, or to extract knowledge of the object properties [1-3]. This process also applies to flying objects such as airplanes or helicopters. In the case of large flying objects, the reverse engineering process is laborious due to their complex construction. In order to analyse the motion of such an object, especially in extraordinary conditions, it is necessary to know its aerodynamic characteristics in all its possible configurations, including the deflection of the control surfaces.

Such a problem arose during the investigation of the Tu-154M aircraft control capabilities. In this case, the basic problem was that most of the aerodynamic characteristics of this aircraft were unknown. Fortunately, the real object was available, i.e. the Tu-154M aircraft, and thanks to that the reverse engineering technique could be used to determine its aerodynamic characteristics.

At the beginning, the external geometry of the aircraft was precisely determined using the scanning method. This work was done by the Military University of Technology (Warsaw. Poland). Then, based on the obtained geometry, the Military University of Technology manufactured the aircraft wind tunnel model in 1:40 scale. The model mapped all aircraft control surfaces and enabled their deflection at the same ranges as they are used on the real object. Furthermore, the model mapped all the gaps between these movable control surfaces and the main wing part, fin or horizontal tail. Based on the obtained wind tunnel tests the aircraft model aerodynamic coefficients were calculated.

The wind tunnel tests of the Tu-154M aircraft model were performed in the Institute of Aviation's (IoA) low speed wind tunnel T-1 (of the $1.5 \mathrm{~m}$ diameter test section) at the undisturbed 
velocity, $\mathrm{V} \infty=40 \mathrm{~m} / \mathrm{s}$ (which corresponds to Reynolds number, $\operatorname{Re}=0.35 \times 10^{6}$ ).

The investigation presented in the article was performed within framework of the project "LARE" (Large Aircraft Reverse Engineering) financed by the Ministry of National Defence Republic of Poland.

\section{Experimental setup and instrumentation}

\subsection{Wind tunnel}

The experimental investigations discussed in the article were performed in the Institute of Aviation's low speed wind tunnel T-1 [4]. The T-1 wind tunnel is a closed-circuit continuous-flow wind tunnel with a $1.5 \mathrm{~m}$ diameter of the open test section, Fig. 1. The controlled range of freestream velocity is $\mathrm{V}_{\infty}=15-40 \mathrm{~m} / \mathrm{s}$. The turbulence level of the flow in the test section is about 0.5 percent. The wind tunnel driving system consists of four-bladed fan powered by a $55 \mathrm{HP}$ AC motor.

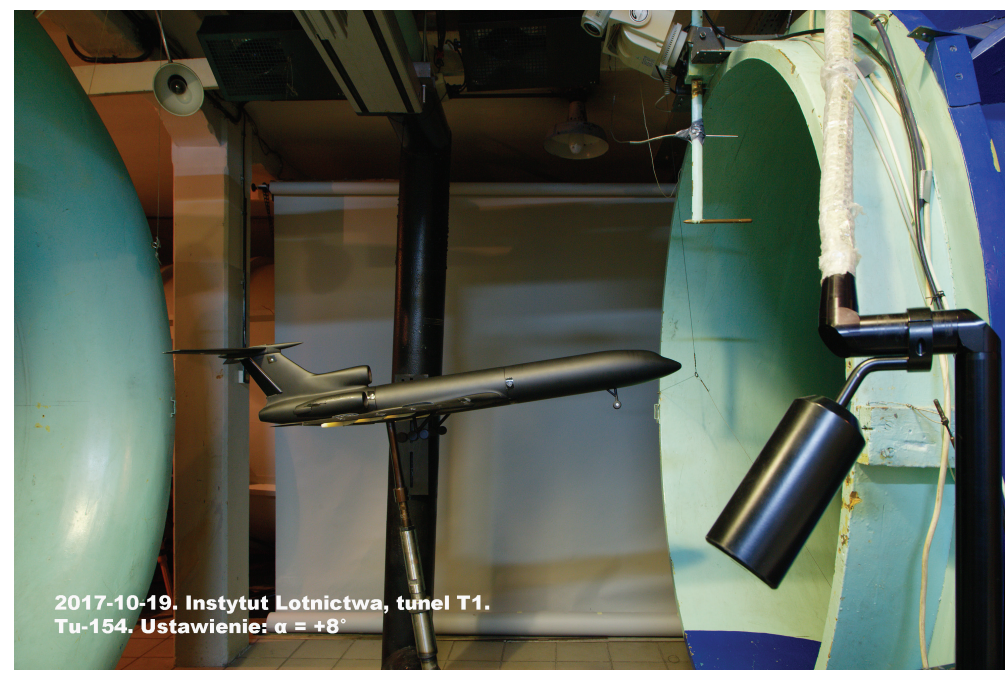

Fig. 1. Model of the Tu-154M aircraft in low speed wind tunnel T-1

\subsection{Tested model}

The wind tunnel tests were performed using Tu-154M aircraft model in 1:40 scale. The model was designed and manufactured by the Military University of Technology basing on the Tu-154M aircraft geometry obtained by full-scale object scanning as well as on the wind tunnel model requirements. The model was fully manufactured in the rapid prototyping technology. The aircraft model was equipped with the presented below control surfaces. All the control surfaces could be deflected at the same ranges as they are used on the real object, i.e.:

- Flaps $\left(\delta_{\mathrm{F}}=0^{\circ}, 36^{\circ}\right)$,

- Elevator $\left(\delta_{\mathrm{h}}=-20^{\circ}-25^{\circ}\right.$ every $\left.5^{\circ}\right)$,

- $\operatorname{Rudder}\left(\delta_{\mathrm{V}}= \pm 25^{\circ}\right.$ every $\left.5^{\circ}\right)$,

- Ailerons (left and right) $\left(\delta_{\mathrm{L}}=\delta_{\mathrm{R}}= \pm 20^{\circ}\right.$ every $\left.5^{\circ}\right)$,

- Slats (extended or retracted),

- Spoilers $\left(\delta_{\mathrm{S}}=0^{\circ}, 15^{\circ}, 30^{\circ}, 50^{\circ}\right)$.

The slats and flaps could be situated only in the two position, i.e. extended or retracted. The spoilers could be situated at $\delta_{\mathrm{S}}=0^{\circ}, 15^{\circ}, 30^{\circ}, 50^{\circ}$. The rest of the control surfaces were movable. The model mapped all the gaps between presented above control surfaces and the main wing part, fin or horizontal tail. In addition to the mentioned above control surfaces in the tested model the horizontal tail angle of inclination could be change at $\delta_{\mathrm{HT}}=0^{\circ},-3^{\circ},-8.5^{\circ}$. 
The Tu-154M aircraft model was tested in a number of its configurations marked in the Figures as follows:

$\delta_{\mathrm{F}} / \delta_{\mathrm{S}} / \delta_{\mathrm{L}} / \delta_{\mathrm{R}} / \delta_{\mathrm{h}} / \delta_{\mathrm{V}} / \delta_{\mathrm{HT}}$

where:

$\delta \mathbf{F}-$ flap deflection angle [deg],

$\delta$ s - spoilers deflection angle [deg],

$\delta_{\mathrm{L}}$ - left wing aileron deflection angle [deg], positive value - downward deflection,

$\delta_{\mathbf{R}}$ - right wing aileron deflection angle [deg], positive value - downward deflection,

$\delta \mathbf{h}$ - elevator deflection angle [deg], positive value - downward deflection,

$\delta \mathbf{v}$ - rudder deflection angle [deg], positive value - deflection towards the left wing,

$\delta_{\text {HT }}$ - horizontal tail inclination angle [deg], positive value - increases the aircraft angle of attack.

\subsection{Measurement technique}

The tested model of the Tu-154 M aircraft in 1:40 scale was mounted in the wind tunnel testing area on the bottom support, to which a six-component aerodynamic balance FFA- I-646-2 (placed inside the model) was attached, Fig. 1.

The aerodynamic characteristics presented in this article refer to the coordinate system (XOYZ) associated with the undisturbed flow direction (along the OX axis), Fig. 2. The figure also shows the coordinate system associated with the model $\left(\mathrm{X}_{0} \mathrm{OY}_{0} \mathrm{Z}_{0}\right)$ - where the fuselage axis coincides with the axis $\mathrm{OX}_{0}$ - and angles of rotation between these systems, i.e. the angle of attack $\alpha$ and the sideslip angle $\beta$. The $\mathrm{OX}_{0}$ and $\mathrm{OZ}_{0}$ axes lie in the airplane's plane of symmetry. The position of the centre of the coordinate system $\mathrm{O}$ is defined as follows:

- the fuselage axis of symmetry,

- $25 \%$ the Middle Aerodynamic Chord (MAC), i.e. $0.581 \mathrm{~m}$ from the model nose.

The geometric data of the Tu-154 M aircraft model adopted to the aerodynamic coefficients calculation are presented below:

- Wing surface, $\mathrm{S}=0.1125 \mathrm{~m}^{2}$,

- Middle aerodynamic chord MAC $=0.132 \mathrm{~m}$ (reference length for the pitching moment $\mathrm{M}_{\mathrm{m}}$ ),

- Wing span $b=0.939 \mathrm{~m}$ (reference length for the rolling moment $\mathrm{M}_{1}$ and yawing moment $\mathrm{M}_{\mathrm{n}}$ ).

The aerodynamic characteristics of the Tu-154M aircraft models in the 1:40 scale presented in this article take into account corrections related to the aerodynamic balance deflection due to the aerodynamic forces and moments impact, and wind tunnel corrections developed basing on literature [5-9].

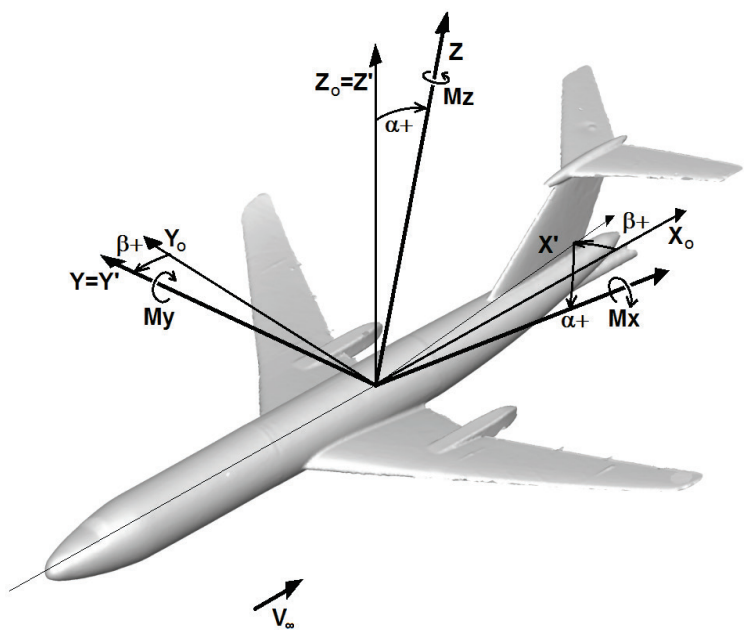

Fig. 2. Coordinate system 


\section{Wind tunnel tests results}

The wind tunnel tests of the Tu-154M aircraft model were performed in the Institute of Aviation's (IoA) low speed wind tunnel T-1 at the undisturbed velocity, Vo $=40 \mathrm{~m} / \mathrm{s}$ (which corresponds to Reynolds number, $\operatorname{Re}=0.35 \times 10^{6}$ and in the range of angles of attack $\alpha=-8^{\circ}-23^{\circ}$. The impact of the some control surfaces deflection on the basic Tu-154M aircraft aerodynamic characteristics was measured.

\subsection{Flap deflection}

In Fig. 3-5 the impact of the flap deflection on the lift $\left(C_{L}\right)$, drag $\left(C_{D}\right)$ and pitching moment $\left(\mathrm{C}_{\mathrm{M}}\right)$ coefficients versus the angle of attack is presented.

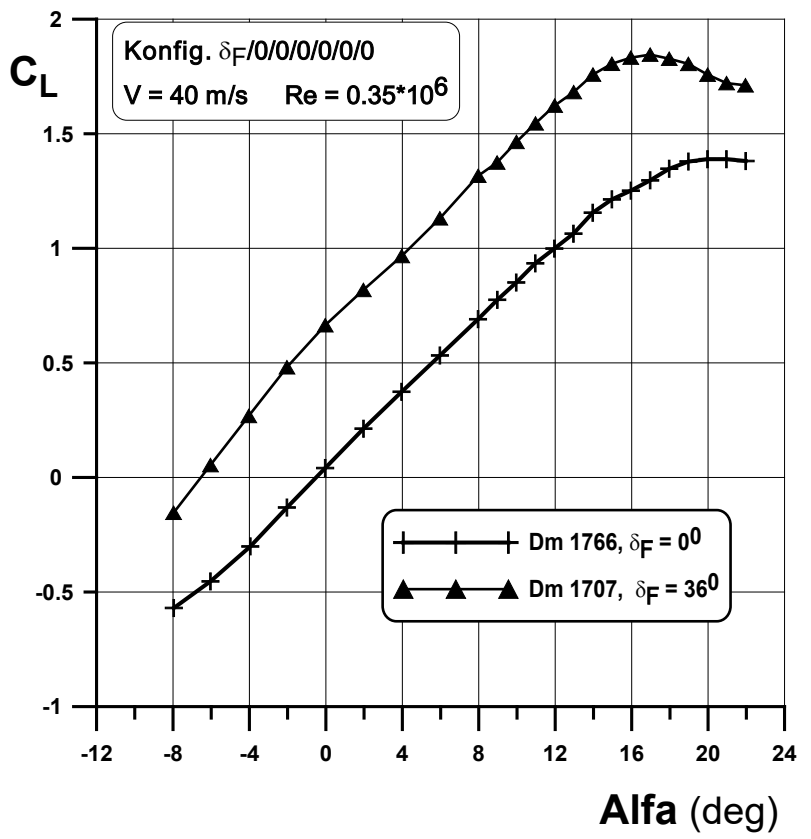

Fig. 3. The impact of the flap deflection on the lift coefficient versus the angle of attack

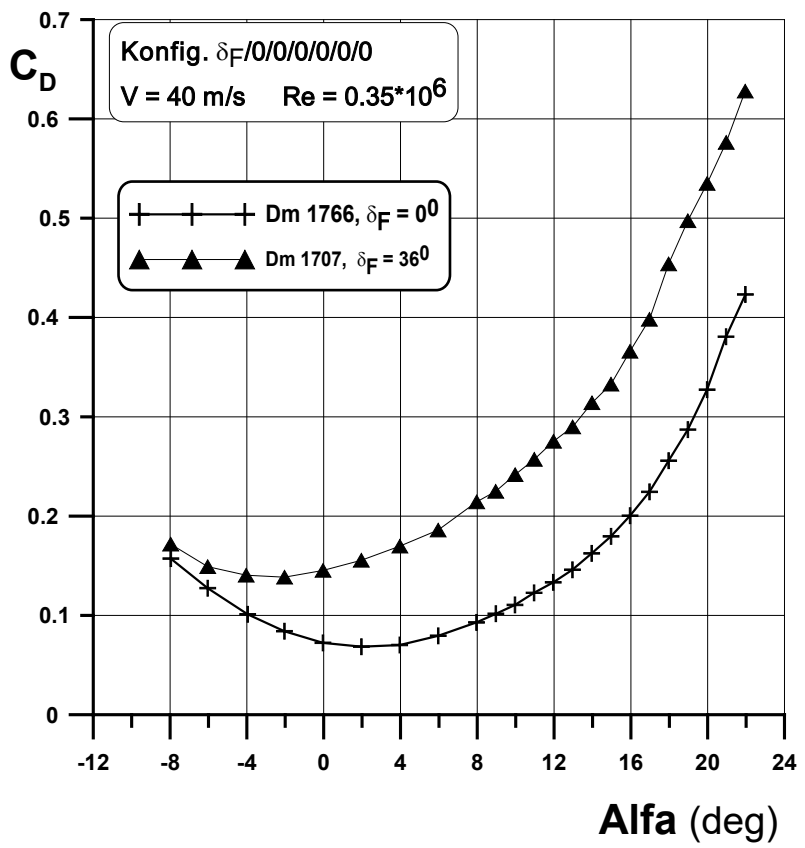

Fig. 4. The impact of the flap deflection on the drag coefficient versus the angle of attack 


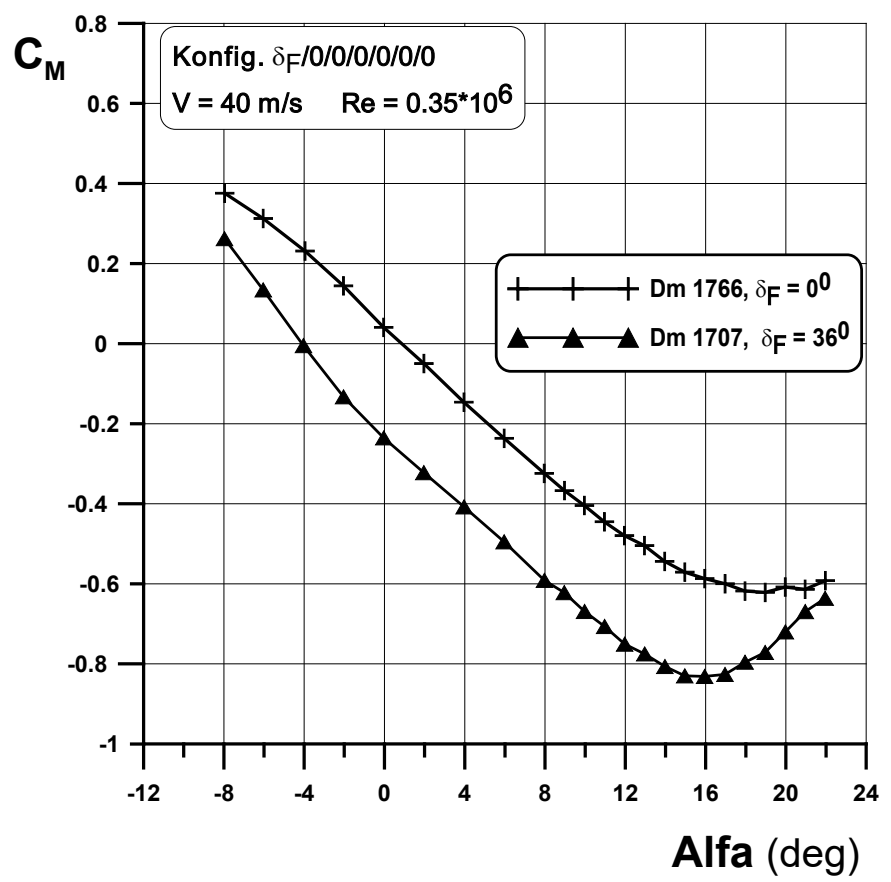

Fig. 5. The impact of the flap deflection on the pitching moment coefficient versus the angle of attack

\subsection{Spoilers deflection}

In Fig. 6 and 7, the impact of the spoiler deflection on the drag $\left(\mathrm{C}_{\mathrm{D}}\right)$ and pitching moment $\left(\mathrm{C}_{\mathrm{M}}\right)$ coefficients versus the angle of attack is presented.

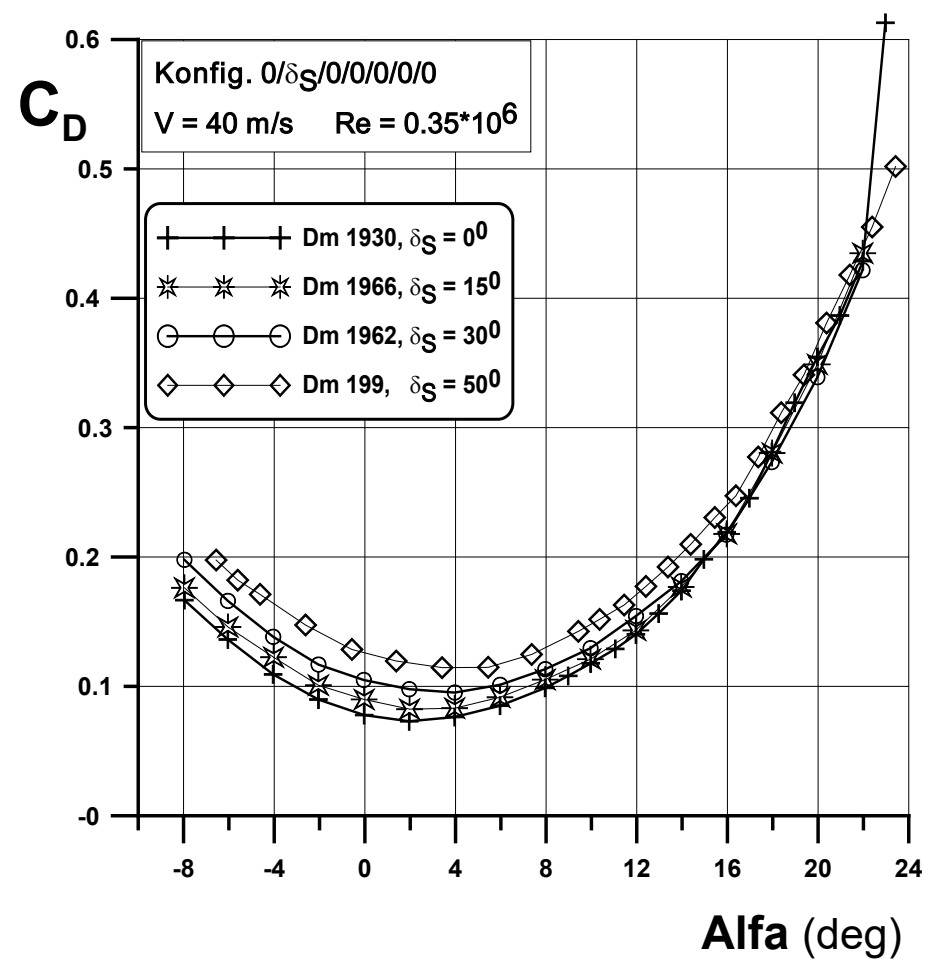

Fig. 6. The impact of the spoilers' deflection on the drag coefficient versus the angle of attack

\subsection{Elevator deflection}

In Fig. 8, the impact of the elevator deflection on the pitching moment coefficients $\left(\mathrm{C}_{M}\right)$ versus the angle of attack is presented. 


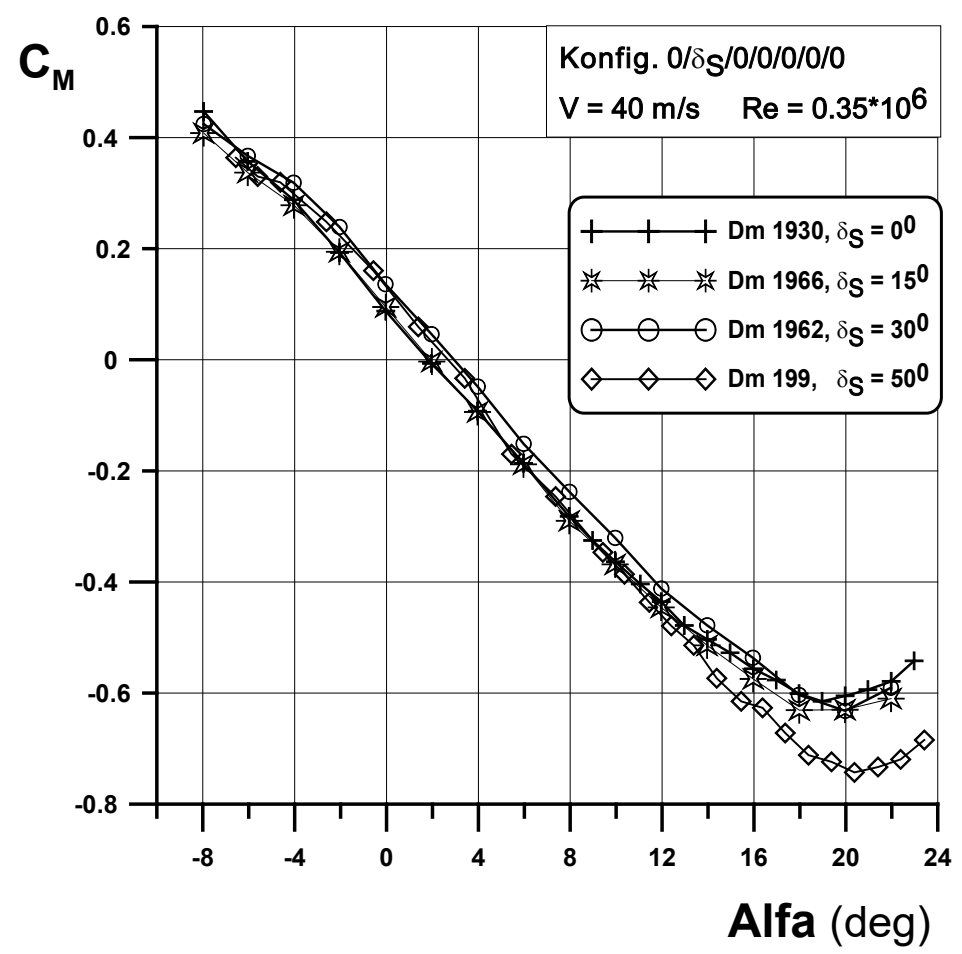

Fig. 7. The impact of the spoilers' deflection on the pitching moment coefficient versus the angle of attack

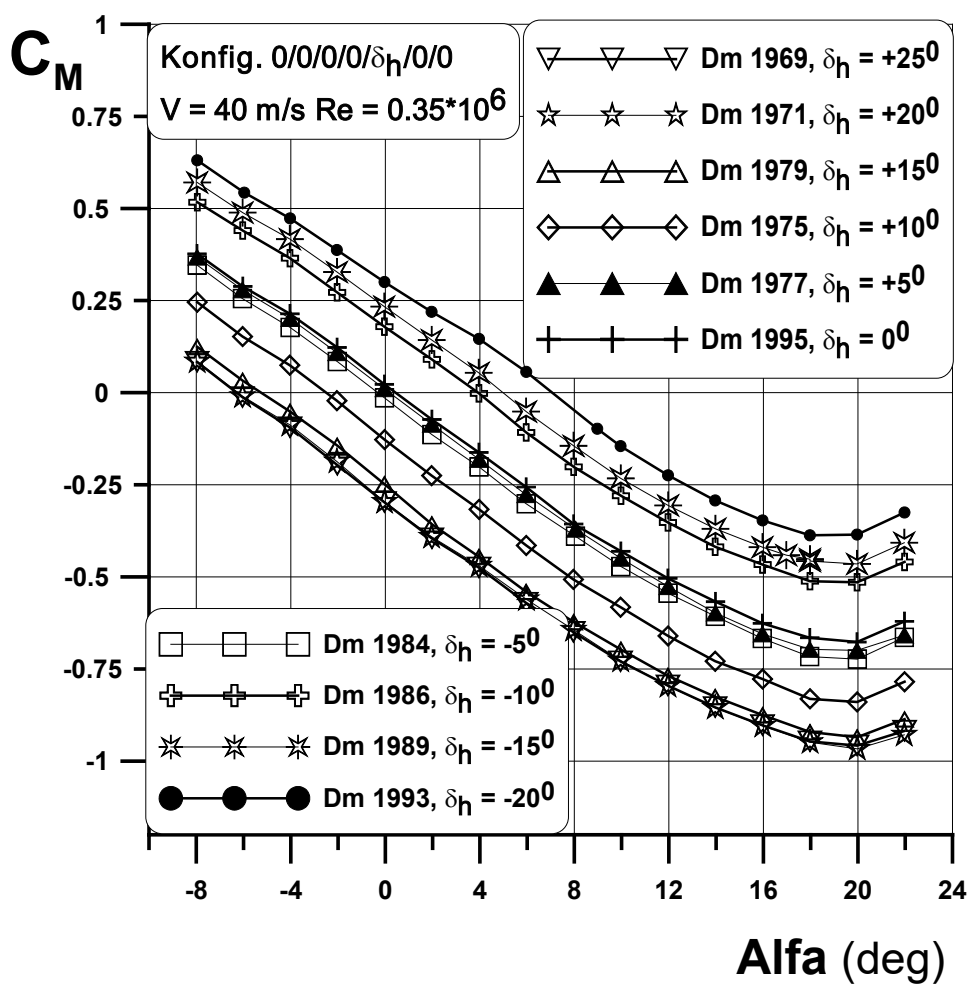

Fig. 8. The impact of the elevator deflection on the pitching moment coefficient versus the angle of attack

\subsection{Rudder deflection}

In Fig. 9 , the impact of the rudder's deflection on the yawing moment coefficients $\left(C_{n}\right)$ versus the angle of attack is presented. 


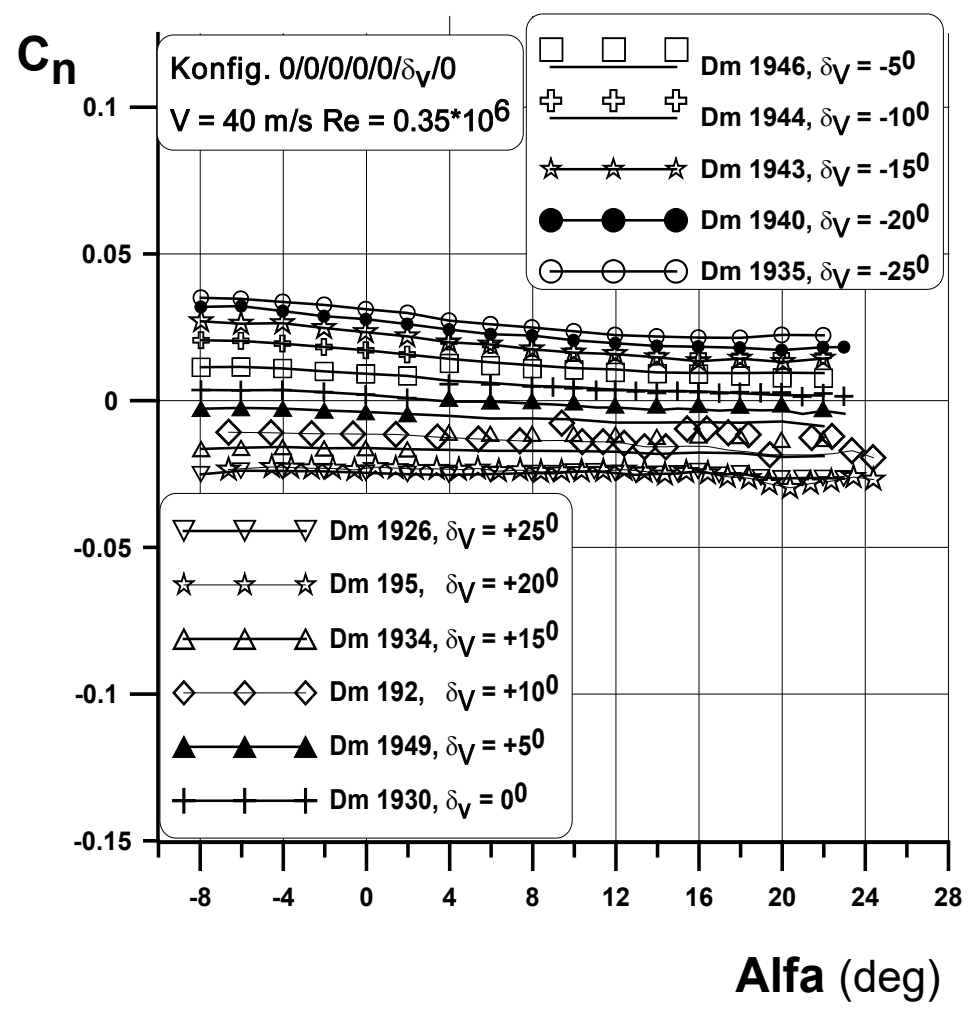

Fig. 9. The impact of the rudder deflection on the yawing moment coefficient versus the angle of attack

\section{Conclusions}

The wind tunnel tests of the Tu-154M aircraft model were performed in the Institute of Aviation's (IoA) low speed wind tunnel T-1 (of the $1.5 \mathrm{~m}$ diameter test section) at the undisturbed velocity, $\mathrm{V} \infty=40 \mathrm{~m} / \mathrm{s}$.

The research has led to the following conclusions:

- The aircraft flaps deflection from $\delta_{\mathrm{F}}=0^{0}$ to $\delta_{\mathrm{F}}=36^{0}$ results in:

- a significant increase of the aircraft drag coefficient with the increase of the angle of attack from $\Delta \mathrm{C}_{\mathrm{D}} \sim 0$ at $\alpha=-8^{0}$ to $\Delta \mathrm{C}_{\mathrm{D}} \sim 0.2$ at $\alpha=23^{0 \prime}$,

- a significant increase of the aircraft lift coefficient by $\Delta \mathrm{C}_{\mathrm{L}} \sim 0.5$,

- a decrease of the pitching moment coefficient by $\Delta \mathrm{C}_{\mathrm{M}} \sim 0.25$.

- The aircraft spoilers deflection results in:

- an increase of the aircraft drag coefficient, in particular in the range of lower angles of attack, i.e. at the range $-8^{0} \leq \alpha \leq 8^{0}$. For example at $\alpha=0^{0}$, after the spoilers deflection from the not deflected position, i.e. $\delta_{\mathrm{S}}=0^{0}$ to $\delta_{\mathrm{S}}=50^{\circ}$, the aircraft drag coefficient increases by $\Delta \mathrm{Cx} \sim 0.05$,

- a decrease of the aircraft pitching moment coefficient at the range of the highest measured angles of attack, i.e. $-14^{0} \leq \alpha \leq 23^{0}$ up $\Delta \mathrm{C}_{\mathrm{M}} \sim-0.15$.

- The aircraft elevator deflection results in:

- a significant change of the aircraft pitching moment coefficient, which depends on the angle of elevator deflection. For example, after deflecting the elevator at the angle $\delta_{\mathrm{h}}=-$ $20^{0}$, the aircraft pitching moment coefficient increases by $\Delta \mathrm{Cmy} \sim 0.27$ in comparison with the undeflected position.

- The aircraft rudder deflection results in:

- a change of the aircraft yawing moment coefficient. For example, when the rudder is deflected to the angle $\delta_{\mathrm{V}}=-25^{0}$, aircraft yawing moment coefficient increases by $\Delta \mathrm{Cmz} \sim$ 0.027 . 


\section{References}

[1] Varady, T., Martin, R., Cox, J., Reverse engineering of geometric models - an introduction, Computer-Aided Design, Vol. 29 (4), pp. 255-268, 1997.

[2] Eldad, E., Reversing: Secrets of Reverse Engineering, Structures in Challenging Environments: Dynamics, Controls, Smart Structures, Health Monitoring and Sensors, Wiley Publishing, 2005.

[3] Olejnik, A., Kiszkowiak, Ł., Dziubiński, A., 16th Biennial International Conference on Engineering, Science, Construction and Operations in Challenging Environments, Cleveland 2018.

[4] Wiśniowski, W., Polish Wind Tunnels on the Background of World Tunnels, Scientific Library of Institute of Aviation, 2016.

[5] Pope, A., Rae, W., Low-Speed Wind Tunnel Testing, Wiley-Interscience Publication, 1984.

[6] Mair, W., Gamble, H., The effect of model size on measurements in the R.A.E. high speed tunnel, Drag of two-dimensional symmetrical aerofoils at zero incidence, A.R.C.R. \& M. No. 2527, 1944.

[7] Tropea, C., Yarin, A., Foss, J., Handbook of Experimental Fluid Mechanics, Springer, 2007.

[8] Steinle, F., Stanewsky, E., Wind Tunnel Flow Quality and Data Accuracy Requirements, AGARD Advisory Report, No. 184, 1982.

[9] Krzysiak, A., Necessary Wind Tunnel Tests Conditions of Proper Two- and ThreeDimensional Measurements, Journal of KONES, Vol. 3, (25), pp. 315-322, 2018.

Manuscript received 08 July 2019; approved for printing 10 September 2019 